\title{
Nutritional Properties and In Vitro Antidiabetic Activities of Blue and Yellow Corn Extracts: A Comparative Study
}

\author{
Aleksandra J. Smorowska, ${ }^{1}$ Anna K. Żołnierczyk ${ }^{D},{ }^{2}$ Agnieszka Nawirska-Olszańska ${ }^{1},{ }^{1}$ \\ Józef Sowiński $(\mathbb{0})^{3}$ and Antoni Szumny $\mathbb{1}^{2}$ \\ ${ }^{1}$ Department of Fruit, Vegetable and Plant Nutraceutical Technology, The Faculty of Biotechnology and Food Science, \\ Wrocław University of Environmental and Life Sciences, Ul. Chetmońskiego 37, 51-630 Wrocław, Poland \\ ${ }^{2}$ Department of Chemistry, The Faculty of Biotechnology and Food Science, \\ Wrocław University of Environmental and Life Sciences, Ul. C. K. Norwida 25, 50-375 Wrocław, Poland \\ ${ }^{3}$ The Faculty of Life Sciences and Technology, Institute of Agroecology and Plant Production, \\ Wrocław University of Environmental and Life Sciences, Pl. Grunwaldzki 24A, 50-363 Wrocław, Poland
}

Correspondence should be addressed to Anna K. Żołnierczyk; anna.zolnierczyk@upwr.edu.pl

Received 8 August 2020; Revised 10 January 2021; Accepted 15 January 2021; Published 25 January 2021

Academic Editor: Seyed Mohammad Taghi Gharibzahedi

Copyright (C) 2021 Aleksandra J. Smorowska et al. This is an open access article distributed under the Creative Commons Attribution License, which permits unrestricted use, distribution, and reproduction in any medium, provided the original work is properly cited.

\begin{abstract}
The objective of this research was to designate and identify the profile of fatty acids, sterols, and polyphenol compounds and to demonstrate the antidiabetic activity, in blue corn extracts (BCE) in comparison with the yellow variant of this raw material. All of the maize lines, including the blue corn, were grown in Europe (southwestern part of Poland) and not in the place of origin (South America). In the extracts of the blue corn variety, eight anthocyanin compounds were isolated. The compound found in the largest amount was pelargonidin, followed by cyanidin-3-glucoside and other glycoside derivatives. Unsaturated fatty acids were the main ones found in the lipid fraction of blue and yellow corn, including linoleic acid and oleic acid. Saturated fatty acids, such as stearic and palmitic acid, were present in smaller amounts. The blue corn's sterol profile was similar to other varieties of this corn, with $\beta$-sitosterol and campesterol occurring in the largest amount, alongside smaller amounts of stigmastanol and stigmasterol. The blue corn variety was characterized by a high content of polyphenolic compounds, which show several biological activities, including antidiabetic activity. The strongest in vitro antidiabetic effect was found in the blue corn lines. Among the polyphenolic compounds in both the blue and yellow corn varieties, in the largest amounts, were caffeic acid, procyanidin B2, and gallic acid. Despite the known and proven biological activity of polyphenolic compounds, the fat fraction showed the highest in vitro antidiabetic activity in the BCE studied.
\end{abstract}

\section{Introduction}

The mountainous terrain of Peru is the place of origin of blue corn. From there, the cultivation of this grain spread to Mexico, Guatemala, and Bolivia. Currently, blue corn is grown all over the world, though most widely in South America. On a smaller scale, cultivation trials have been undertaken in Poland, Turkey, the United States, and many other countries $[1,2]$.

The colour of blue corn stems from the accumulation of anthocyanins in the aleurone layer that surrounds the endosperm in the kernels. The examined structure of anthocyanins in blue varieties showed 16 different anthocyanidins, including, in the largest amount, cyanidine-3glucoside constituting approximately $75 \%$ of the anthocyanidins, followed by pelargonidin-3-glucoside and peonidin-3-glucoside [2, 3].

The structure of blue corn grain allows for economic use of the raw material. The outer layer of the grain containing a large amount of anthocyanins can be removed to obtain natural dyes, and the remaining elements can be used to make flour, ethanol, feed, food additives, and many other 
substances. Corn grains are a raw material rich in carbohydrates-mainly starch, the content of which ranges from 58.0 to $71.5 \%$. The protein content in the blue varieties is higher compared to yellow and white corn varieties, from 9.1 to $13.1 \%$. The lipid content of blue varieties ranges from 4.5 to $6 \%$ [2]. The main fatty acids found in corn grains are unsaturated fatty acids, including linoleic and oleic acids (about $12 \%$ each). Saturated fatty acids, such as stearic and palmitic acids, are also present in smaller amounts. The lipid content ranges from 4.3 to $6.9 \%$. The composition of blue corn is variable and depends on many factors, including climatic conditions, variety, cultivation method, and fertilization $[2,4,5]$.

The polyphenolic organic compounds contained in blue corn have a number of biological activities, including antidiabetic [6], antioxidant, and anti-inflammatory activity [7]. They participate in cellular interactions and the activation of enzymes and receptors, regulate apoptosis, and support the nervous system $[8,9]$. They play an important role in the prevention of cardiovascular disease, are used in anticancer therapy, and also contribute to the prevention of obesity, hypoglycemia, and diabetes $[10,11]$.

Among cereals, blue corn is one of the significant sources of anthocyanins. Cereal products made from this variety of corn may be characterized not only by an interesting colour, but also by a high content of nutrients and bioactive elements [12]. Encapsulated powders of blue corn extract could be natural food colorants with antioxidant properties [13].

Corn silk (stigma of Zea mays, stigma Maydis) is well established in the treatment or prevention of several diseases, like cystitis, edema, kidney stones, prostate disorder, bedwetting, and urinary infections [14]. The main purpose of their use is weight control and supporting the treatment of diabetes mellitus [15]. Although the chemical composition of corn silk includes compounds known for biological activity, such as polyphenols (like flavonoids) and monoterpenoids, the antidiabetic activity of this material is associated with phytosterols (mainly stigmasterol) [14].

Inhibitors of carbohydrate metabolizing enzymes are effective in controlling the levels of postprandial hyperglycemia via control of starch metabolism $[16,17]$. They are known as $\alpha$-amylase inhibitors and are present in corn seeds. Alkaloids, flavonoids, phenols, saponins, tannins, and phytosterols present in corn silk ethanolic extracts have demonstrated inhibitory activity against $\alpha$-amylase and $\alpha$-glucosidase, compared with standard acarbose [18].

In 2020, Damian-Medina et al. [6] analysed the in silico antidiabetic potential of phenolic compounds present in blue corn [6]. The objective of the research was to designate and identify the profile of fatty acids, sterols, and polyphenol compounds and to demonstrate the antidiabetic activity in blue corn extracts in comparison with the yellow variant of this raw material. Molecular docking highlighted that cyanidin 3-glucoside, delphinidin 3-glucosid, and petunidin 3glucoside interaction with some proteins $(11 \beta-\mathrm{HS}$, GFAT, PTP, and RTK) play a key role in diabetes mellitus. This work proves the interaction of blue corn extracts cultivated in Europe (southwestern part of Poland) with other factors affected by diabetes $\alpha$-glucosidase.

\section{Materials and Methods}

2.1. Experimental Materials. In 2014, a few blue corn lines (200 grains of each) were obtained from the CIMMYT gene bank (International Maize and Wheat Improvement Centre) in Mexico, specifically CHIH 365, CHIH 367, and $\mathrm{CHIH}$ 503 , to check the suitability of blue maize cultivation in Polish environmental conditions (south-west). From observational studies, only three lines set grains and reached full maturity in the moderate zone. In 2015, in the recommended spatial isolation (minimum $230 \mathrm{~m}$ ), selected lines were multiplied at the Research Station of the Horticulture Department of the University of Environmental and Life Sciences in Wroclaw. Currently, the amount of propagated material from each of the selected populations allows for comparative studies, which were scheduled for 2017.

The research material consisted of three lines of blue corn (CHIH 365, CHIH 367, and CHIH 503) and two yellow varieties (OPOKA and KUSKUN) harvested from the Research Station of the Horticulture Department of Lower Silesia in 2017.

Before testing, all varieties of maize were shredded and then placed in sealed packages.

2.2. Preparation of Extracts (Blue Corn Extracts-BCE). About $100 \mathrm{~g}$ of dried (8\% moisture) blue (three lines: $\mathrm{CHIH}$ 365, CHIH 367, and CHIH 503) or yellow (KUSKUN or OPOKA) corn seeds was separately homogenized and ground. Next, the obtained flour was extracted at $60^{\circ} \mathrm{C}$ for $24 \mathrm{~h}$ in a solution of $80 \%$ methanol, with the addition of $1 \%$ $\mathrm{HCl}(500 \mathrm{~mL})[19,20]$. Prior to the determinations, the samples were centrifuged at $5000 \mathrm{rpm}$ for $10 \mathrm{~min}$. Then, the supernatant was concentrated on a rotary vacuum evaporator to approx. $1.7 \mathrm{~g}$ of residue.

2.3. Determination of Antidiabetic Activity. To determine the antidiabetic activity, the diffusion method was used [21, 22]. Fifteen milligrams of obtained (freeze-dried powder or residue) samples was dissolved in $0.5 \mathrm{~mL}$ dimethyl sulfoxide (DMSO) and transferred to Eppendorf tubes as a stock solution. To demonstrate the effectiveness of the method, the primary extract was diluted 5, 10, 25, and 50 times using DMSO. Petri plates were filled with the prepared agar medium (3\%) with starch (1\%), and after solidification of the substrate, cylindrical wells with a diameter of $0.5 \mathrm{~cm}$ were cut. The negative control (T-) was a solution of $25 \mu \mathrm{L}$ acarbose solution $\left(50 \mathrm{mg} / 1 \mathrm{~mL} \cdot \mathrm{H}_{2} \mathrm{O}\right)$ compound contained in antidiabetic drugs $+25 \mu \mathrm{L}$ of pork $\alpha$-amylase solution $\left(6 \mathrm{mg} / 10 \mathrm{~mL} \cdot \mathrm{H}_{2} \mathrm{O}\right)$. The positive control $(\mathrm{T}+)$ was a solution of $25 \mu \mathrm{L}$ of water $+25 \mu \mathrm{L}$ of pork $\alpha$-amylase $(6 \mathrm{mg} / 10 \mathrm{~mL}$ of $\mathrm{H}_{2} \mathrm{O}$ ). The proper tests were $25 \mu \mathrm{L}$ of the tested blue-corn extract or fractions from stock solutions $+25 \mu \mathrm{L}$ of pork $\alpha$-amylase $\left(6 \mathrm{mg} / 10 \mathrm{~mL} \cdot \mathrm{H}_{2} \mathrm{O}\right)$. All solutions were introduced into holes cut out of the agar. The prepared plates were incubated for 24 hours at $35-37^{\circ} \mathrm{C}$. After incubation, the plates were dyed with iodine and the emergent clear zones were measured, and the degree of inhibition was calculated. 
The hole with the positive control $(\mathrm{T}+)$ was taken as $100 \%$ clear zone. The tests were performed in triplicate.

\subsection{Determination of Preparative Thin-Layer Chromatogra-} phy (TLC). Preparative thin-layer chromatography was performed on $20 \times 20 \mathrm{~cm}$ glass plates coated with 1000 micron layers of silica gel GF (Uniplate ${ }^{\mathrm{TM}}$ ). The plate was applied and residue obtained as in Section 2.1, after being dissolved in $1 \mathrm{~mL} 80 \%$ methanol with the addition of $1 \%$ $\mathrm{HCl}$. The plates were developed with eluent hexane : acetone $(1: 3, \mathrm{v}: \mathrm{v})$ in a sealed glass TLC chamber at ambient temperature. The plates were then air-dried, and the separated bands were scraped from the plates. The separated bands were extracted with acetone $(15 \mathrm{~mL})$ at ambient temperature for $24 \mathrm{~h}$. The extracts were concentrated on a rotary vacuum evaporator and dissolved in $0.5 \mathrm{~mL}$ DMSO. To determine the antidiabetic activity in the obtained extracts, the method described in Section 2.3 was used. The procedure was repeated seven times.

2.5. Determination of Fatty Acid Composition. The sample obtained in Section 2.1 was submitted to basic hydrolysis using $\mathrm{KOH} / \mathrm{MeOH} / \mathrm{BF}_{3}$ approach by Kupczyński et al. [23]. The prepared samples were dissolved in $2 \mathrm{~mL}$ of tert-butyl methyl ether (MTBE) and the fatty acid profile was analysed using a gas chromatograph coupled with mass detection (GC/MS). Compounds were identified by comparison: (a) obtained spectra with NIST14 database; (b) retention times of standards (Aldrich mix 37 FAME).

2.5.1. GC-MS Conditions. The analysis was performed on Shimadzu GCMS-QP2020 using a ZB-WAXplus column $(30 \mathrm{~m} \times 0.25 \mathrm{~mm} \times 0.25 \mu \mathrm{m})$. The split was set at 100:1 value; helium was used as the carrier gas $(1.0 \mathrm{~mL} / \mathrm{min}$. in constant flow mode). The dispenser temperature was $260^{\circ} \mathrm{C}$. Column ramp temperature was $160^{\circ} \mathrm{C}(5 \mathrm{~min})$ to $200^{\circ} \mathrm{C}\left(2^{\circ} \mathrm{C} / \mathrm{min}\right)$ to $250^{\circ} \mathrm{C}\left(10^{\circ} \mathrm{C} / \mathrm{min}\right)$ and held 4 for min. The duration of the whole analysis was $34 \mathrm{~min}$. Detector temperature $250^{\circ} \mathrm{C}$ full scan in the range of 50-500 AU.

2.6. Determination of the Sterol Profile. The sample obtained in Section 2.1 was submitted to BSTFA derivatization according to Chua et al. [24]. The samples were then dissolved in $2 \mathrm{~mL}$ of MTBE and the sterol profile was analysed using a gas chromatograph with mass detection (GC/MS). Phytosterol compounds were identified by comparison with (a) obtained spectra from the NIST14 database and (b) retention times of available standards (Aldrich).

2.6.1. GC-MS Conditions. The analyses of obtained fractions were performed on Shimadzu GCMS-QP2020 using a ZB-5 column $(30 \mathrm{~m} \times 0.25 \mathrm{~mm} \times 0.25 \mu \mathrm{m}$, for sterols $)$ or $\mathrm{ZB}$ WAXMS $(30 \mathrm{~m} \times 0.25 \mathrm{~mm} \times 0.25 \mu \mathrm{m}$ film from Zebron, Phenomenex). The split was set up at 10:1. Helium was used as the carrier gas $(1.0 \mathrm{~mL} / \mathrm{min}$, constant flow mode). For FAME analyses, the following temperature ramp was used: $5^{\circ} \mathrm{C} / \mathrm{min}$ from $80^{\circ} \mathrm{C}$ to $200^{\circ} \mathrm{C}$ then $25^{\circ} \mathrm{C} / \mathrm{min}$ to $260^{\circ} \mathrm{C}$, injector temperature $220^{\circ} \mathrm{C}$, and helium gas carrier at $1 \mathrm{~mL}$ per minute. The injector temperature was $280^{\circ} \mathrm{C}$. Column temperature ramp: $170^{\circ} \mathrm{C}$ to $300^{\circ} \mathrm{C}$ (build-up $5^{\circ} \mathrm{C} / \mathrm{min}$ ), analysis end $300^{\circ} \mathrm{C}$. Duration of the entire analysis: $36 \mathrm{~min}$. Detector temperature $250^{\circ} \mathrm{C}$, full scan in the range of $40-500$.

2.7. NMR Analysis. NMR spectra were recorded in a $\mathrm{CDCl} 3$ solution on an Avance ${ }^{\mathrm{TM}} 600 \mathrm{MHz}$ spectrometer (Bruker, Billerica, MA, USA) or a UnityPlus $500(500 \mathrm{MHz})$ spectrometer and a Gemini $300(75 \mathrm{MHz})$ (Varian, Palo Alto, CA, USA).

2.8. Determination of Polyphenolic Compounds. The sample obtained in Section 2.1 was submitted to UPLC according to Kucharska et al. [25]. The analysis of polyphenolic compounds was determined using the UPLC Acquity system (Waters, Corp., Milford, MA, USA) with DAD (diode array detector). The separation was carried out on a chromatography column BEH Shield C18 $(2.1 \mathrm{~mm} \times 5 \mathrm{~mm} \times 1.7 \mu \mathrm{m})$. The column was thermostated at a temperature of $30^{\circ} \mathrm{C}$, and the test samples were thermostated at $4^{\circ} \mathrm{C}$. Solvents $\mathrm{A}$ and $\mathrm{B}$ were used as the mobile phase. Solvent A was a $4.5 \%$ formic acid solution and B was acetonitrile. The volume of the injected sample was $10 \mu \mathrm{L}$, and the flow rate of the eluents was $0.45 \mathrm{~mL} / \mathrm{min}$. Detection of polyphenolic compounds was carried out at four wavelengths: $520 \mathrm{~nm}$ (anthocyanins), $320 \mathrm{~nm}$ (phenolic acids), $360 \mathrm{~nm}$ (flavonols), and $280 \mathrm{~nm}$ (flavan-3-ols). The concentration of polyphenols was determined by comparison of peak areas in the chromatogram, with the values of the calibration curve. The obtained results are shown in $\mathrm{mg}$ per $100 \mathrm{~g}$ of flour. The determination was performed in triplicate.

2.9. Statistical Analysis. The data was analysed using Statistica 13 software. The Duncan test analysed the differences between means ( $p$ value $<0.05$ ). The tables present average standard deviations.

\section{Results and Discussion}

3.1. Profile of Fatty Acids. The fatty acids profile is shown in Table 1. In blue and yellow varieties corn observed, similar fatty acid profile was identified. In all tested maize variants, oleic, linoleic, palmitic, stearic, and alpha-linolenic acids were detected in the largest quantities.

In the studied lines of blue corn and in the yellow varieties, a similar fatty acid profile was identified. In all tested maize variants, oleic acid, linoleic acid, palmitic acid, stearic acid, and alpha-linolenic acid were detected in the largest quantities.

The highest content of saturated fatty acids (SFA) was found in blue corn from the line CHIH $367(7.63 \mathrm{~g} / \mathrm{kg})$. The most monounsaturated fatty acids (MUFA) were found in yellow corn variety OPOKA $(13.21 \mathrm{~g} / \mathrm{kg})$, and the highest content of polyunsaturated fatty acids (PUFA) was found in 
two lines of blue corn, CHIH $365(13.75 \mathrm{~g} / \mathrm{kg})$ and CHIH 503 $(13.93 \mathrm{~g} / \mathrm{kg})$, and Fraction II of fatty acids from the CHIH 365 line $(14.14 \mathrm{~g} / \mathrm{kg})$. Based on Table 1 , showing the fatty acid profile determined quantitatively in the tested maize varieties, blue corn lines dominated in terms of saturated and polyunsaturated fatty acids. Figure 1 shows the chromatogram of the fatty acid profile of blue maize line CHIH 365.

The marked profile of fatty acids in the blue corn varieties is similar to the data presented by Mutlu et al. [2], who showed that, among the determined fatty acids in the blue variety cultivated in Turkey, oleic acid constituted 52.2\%, linoleic acid constituted $44.8 \%$, and palmitic acid (2.9\%) and stearic acid (0.4\%) were found in smaller amounts [2].

According to Camelo-Méndez et al. [4], the diversity of the fatty acid profile composition in corn grain results from soil and climatic conditions and from the variety of cultivated corn. The profile of fatty acids in the varieties grown in Mexico, presented by Urias-Lugo et al. [26], was similar to the profile of the studied in this paper's blue varieties. Linoleic acid ( $43.3 \%$ to $52.0 \%$ ), oleic acid ( $25.5 \%$ to $35.3 \%)$, and palmitic acid (11.9\% to $17.3 \%)$ were found in the largest amounts. Other acids were found in smaller quantities, including stearic acid ( $0.3 \%$ to $14.0 \%)$, arachidonic acid (0.6\% to $8.8 \%)$, and eicosenoic acid (0.2\% to $1.7 \%)$ [26].

According to Urias-Lugo et al. [26], among the saturated fatty acids found in the varieties grown in Mexico, the most abundant was palmitic acid, and among the polyunsaturated acids was linolenic acid, which accounted for about $50 \%$ of all determined fatty acids. The high content of linolenic acid increases the health and nutritional value of the tested varieties. The average fatty acid content in all blue corn genotypes tested in Mexico was $21 \%$ saturated fatty acids, $29 \%$ monounsaturated, and 50\% polyunsaturated. The average content of saturated fatty acids in the tested varieties grown in Poland was about 59\% saturated fatty acids, about $2 \%$ monounsaturated, and about $39 \%$ polyunsaturated. The average results show a significant difference in the genotype of the varieties grown in terms of the content of saturated and polyunsaturated fatty acids. These differences may result from the longer storage time of the tested varieties, but also from other soil and climatic conditions [26].

3.2. Sterols Profiles. Table 2 shows the average phytosterol content in the tested maize varieties. In the studied lines of blue corn, and in the yellow varieties, a similar phytosterol profile was identified. In all tested maize variants, $\beta$-sitosterol, campesterol, and stigmastanol were found in the largest quantities.

In the CHIH 367 blue maize line and the yellow OPOKA variety, the content of $\beta$-sitosterol was the highest (36.6 and $44.23 \mathrm{mg} / 100 \mathrm{~g}$, respectively). The second most common sterol was campesterol, and it was most abundant in the blue variant of the CHIH 367 and OPOKA lines (approximately $12 \mathrm{mg} / 100 \mathrm{~g}$ ).

Stigmastanol was found in the largest amount in the blue corn lines CHIH 365 and CHIH 503 (from approximately 14 to $12 \mathrm{mg} / 100 \mathrm{~g}$ ). Figure 2 shows the chromatogram of the sterol blue corn CHIH 503 line. The phytosterol profile is in the statement with other reports [27-29]. Moreau found $\beta$-sitosterol and campesterol predominated in corn kernels of sweet maize, at about 27 and $17 \mathrm{mg} / 100 \mathrm{~g}$, respectively. On the other hand, Harabi [30], in the germ of the Astro variety, found 19 and $2.6 \mathrm{mg} / 100 \mathrm{~g}$ of those phytosterols. Phytosterols possess proven antidiabetic activity [30].

Phytosterols can act as ligands for PPARs [31], reduce visceral fat accumulation [32], and reduce the concentration of glycosylated hemoglobin, serum glucose, nitric oxide, and substances that react with thiobarbituric acid, and they can increase serum insulin and pancreatic antioxidants $[30,33,34]$. Other mechanisms of antidiabetic action may be related to the inhibition of glycolytic enzymes such as $\alpha$-amylase. Phytosterols isolated from banana flowers (e.g., $\beta$-sitosterol and 31-norcyclolaudenone) inhibit amylase as an uncompetitive inhibitor, with a $\mathrm{km}$ value of $5.51 \mu \mathrm{g} / \mathrm{mL}$ [35]. Stigmasterol from soy disrupts the GLUT4 glucose transporter, which gives the beneficial effects seen in the treatment of type 2 diabetes mellitus [36]. The phytosterol fraction isolated from the marine algae Sargassum glaucescens, with fucosterol stigmasterol $\beta$-sitosterol predominating, strongly inhibits alpha-amylase in in vitro tests at the value of IC50 $9 \mathrm{mg} / \mathrm{mL}$ [37].

3.3. NMR Analysis of Extracts. Methanolic extraction of blue corn gives the product Fraction I, F-I, which was identified as containing fatty acids with the composition presented in Table 1. Unfortunately, due to the acidic conditions of the extraction process and use of a strong base (potassium hydroxide in boron trifluoride), these results are not unequivocal. The following products could give the same results: (a) triacylglycerides; (b) methyl esters or free fatty acids; and (c) a mixture of the above. To avoid misinterpretations, we decided to perform nuclear magnetic resonance measurements which were less selective, but mild and nondestructive $[38,39]$. On the recorded spectrum in F-I (see Figures S1 and S2 in the Supplementary Materials for the comprehensive image analysis), we unequivocally found pure fatty acid fractions. The ${ }^{13} \mathrm{C}$ spectrum was characteristic to free acids, with visible free carboxylic carbons (174 ppm), double bonds (128.19-130.16), and corresponding aliphatic carbons. No methoxy (for methyl esters) or alkoxy characteristic carbons $(60-70 \mathrm{ppm})$ were on the spectrum.

The ${ }^{1} \mathrm{H}$ and ${ }^{13} \mathrm{C}$ spectrum of Fraction F-II revealed the presence of triacylglyceride, which was proven by the characteristic two doublets of doublets (glycerine methylene protons), as well as the multiplet of methine $(>\mathrm{CH}(\mathrm{O}))$.

\subsection{Polyphenolic Compounds}

3.4.1. Anthocyanins. In the studies on anthocyanins, in blue corn lines, six dominating compounds have been determined (see Table 3 ). The most common is cyanidin3-(6'-malonylglucoside), followed by cyanidin-3-glucoside and peonidin-3-(6'malonyglucoside); these were determined in all the lines tested. The largest amount of anthocyanins was found in the line $\mathrm{CHIH} \mathrm{367,} \mathrm{and} \mathrm{the}$ least was found in the line $\mathrm{CHIH}$ 503. In the studied 
TABle 1: Fatty acid profile quantified $(\mathrm{g} / \mathrm{kg})$ in the BCE and Fraction II.

\begin{tabular}{|c|c|c|c|c|c|c|c|c|c|}
\hline No. & RT & & Fatty acid* & CHIH 365 FI & $\begin{array}{c}\text { CHIH } 365 \mathrm{~F} \\
\text { II }\end{array}$ & CHIH 367 & CHIH 503 & OPOKA & KUSKUN \\
\hline 1 & 7.70 & $\begin{array}{c}\mathrm{C} 14: \\
0\end{array}$ & Tetradecanoic acid & & $0.01 \pm 0.01 \mathrm{a}$ & & & & \\
\hline 2 & 10.25 & $\begin{array}{c}\mathrm{C} 15: \\
0\end{array}$ & Pentadecanoic acid & & $0.02 \pm 0.01 \mathrm{a}$ & & & & \\
\hline 3 & 13.20 & $\begin{array}{c}\mathrm{C} 16: \\
0\end{array}$ & Palmitic acid & & $5.13 \pm 0.29 a$ & & & & \\
\hline 4 & 13.70 & $\begin{array}{c}\text { C16: } \\
1\end{array}$ & Palmitoleic acid (9Z) & & $0.02 \pm 0.01 \mathrm{a}$ & & & & \\
\hline 5 & 13.90 & $\begin{array}{c}\text { C16: } \\
1\end{array}$ & $\begin{array}{c}\text { 11-Hexadecenoic acid } \\
(11 Z)\end{array}$ & & $0.06 \pm 0.01 \mathrm{a}$ & & & & \\
\hline 6 & 16.40 & $\begin{array}{c}\text { C17: } \\
0\end{array}$ & Heptadecenoic acid & & $0.05 \pm 0.01 \mathrm{a}$ & & & & \\
\hline 7 & 17.20 & $\begin{array}{c}\text { C17 : } \\
1\end{array}$ & $\begin{array}{c}\text { Heptadec-10-enoic acid } \\
(10 E)\end{array}$ & & $0.01 \pm 0.01 \mathrm{a}$ & & $0.02 \pm 0.01 \mathrm{a}$ & & $0.02 \pm 0.01 \mathrm{c}$ \\
\hline 8 & 20.01 & $\begin{array}{c}\text { C18: } \\
0\end{array}$ & Stearic acid & & $1.13 \pm 0.033 b$ & & & & \\
\hline 9 & 20.70 & $\begin{array}{c}\text { C18: } \\
1\end{array}$ & Oleic acid & $12.33 \pm 1.05 \mathrm{ab}$ & $12.42 \pm 0.98 \mathrm{~d}$ & & $11.82 \pm 1.01 \mathrm{~b}$ & $12.65 \pm 0.92 \mathrm{~d}$ & $11.18 \pm 1.01 \mathrm{c}$ \\
\hline 10 & 20.85 & $\begin{array}{c}\text { C18: } \\
1\end{array}$ & $\begin{array}{c}\text { 12-Octadecenoic acid } \\
(12 Z)\end{array}$ & & $0.11 \pm 0.02 \mathrm{a}$ & & & & \\
\hline 11 & 22.20 & $\begin{array}{c}\mathrm{C} 18: \\
2\end{array}$ & Linoleic acid & $13.08 \pm 1.07 \mathrm{a}$ & $13.56 \pm 0.75 b$ & $11.39 \pm 0.98 b$ & $11.52 c \pm 0.81 c$ & $11.85 \pm 1.02 \mathrm{ab}$ & $11.22 \pm 1.04 \mathrm{bc}$ \\
\hline 12 & 24.50 & $\begin{array}{c}\text { C18: } \\
3\end{array}$ & $\alpha$-Linolenic acid & $0.45 \pm 0.02 b$ & $0.25 \pm 0.03 \mathrm{~d}$ & & & & \\
\hline 13 & 25.45 & $\begin{array}{c}\text { C18: } \\
2\end{array}$ & 11 Ood & Trace & Trace & Trace & & & \\
\hline 14 & 25.85 & $\begin{array}{c}\text { C18: } \\
2\end{array}$ & $\begin{array}{c}\text { 9,11-Octadecadienoic } \\
\text { acid }(9 Z, 11 E)\end{array}$ & Trace & Trace & Trace & & & \\
\hline 15 & 26.80 & $\begin{array}{c}\mathrm{C} 20: \\
0\end{array}$ & Eicosanoic acid & $0.31 \pm 0.02 \mathrm{ab}$ & $0.21 \pm 0.01 \mathrm{a}$ & $0.35 \pm 0.02 \mathrm{a}$ & & & $0.32 \pm 0.02 \mathrm{ab}$ \\
\hline 16 & 27.20 & $\begin{array}{c}\mathrm{C} 20: \\
1\end{array}$ & 11-Eicosenoic acid (11Z) & $0.12 \pm 0.01 \mathrm{a}$ & $0.15 \pm 0.02 \mathrm{a}$ & & & $0.13 \pm 0.01 \mathrm{a}$ & $0.10 \pm 0.01 \mathrm{a}$ \\
\hline 17 & 28.00 & $\begin{array}{c}\mathrm{C} 18: \\
2\end{array}$ & $\begin{array}{l}\text { Octadeca-10,12-dienoic } \\
\text { acid }(10 E, 12 Z)\end{array}$ & $0.22 \pm 0.01 c$ & $0.33 \pm 0.03 \mathrm{~d}$ & $0.30 \pm 0.02 b$ & $1.10 \pm 0.08 \mathrm{a}$ & $0.01 \pm 0.01 \mathrm{e}$ & $0.11 \pm 0.01 d$ \\
\hline 18 & 30.20 & $\begin{array}{c}\mathrm{C} 22: \\
0\end{array}$ & Docosanoic acid & $0.13 \pm 0.01 \mathrm{~d}$ & $0.24 \pm 0.01 \mathrm{~d}$ & $0.22 \pm 0.01 \mathrm{a}$ & $0.19 \pm 0.01 b$ & $0.22 \pm 0.02 \mathrm{a}$ & $0.14 \pm 0.01 \mathrm{~d}$ \\
\hline 19 & 33.25 & $\begin{array}{c}\mathrm{C} 24: \\
0\end{array}$ & Tetracosanoic acid & $0.13 \pm 0.01 c$ & $0.12 \pm 0.02 \mathrm{~d}$ & $0.16 \pm 0.01 b$ & $0.14 \pm 0.01 c$ & $0.25 \pm 0.02 a$ & $0.25 \pm 0.02 \mathrm{a}$ \\
\hline
\end{tabular}

* Expressed as methyl esters according to GC-MS chromatogram. a-e: homogeneous groups according to Duncan's test.

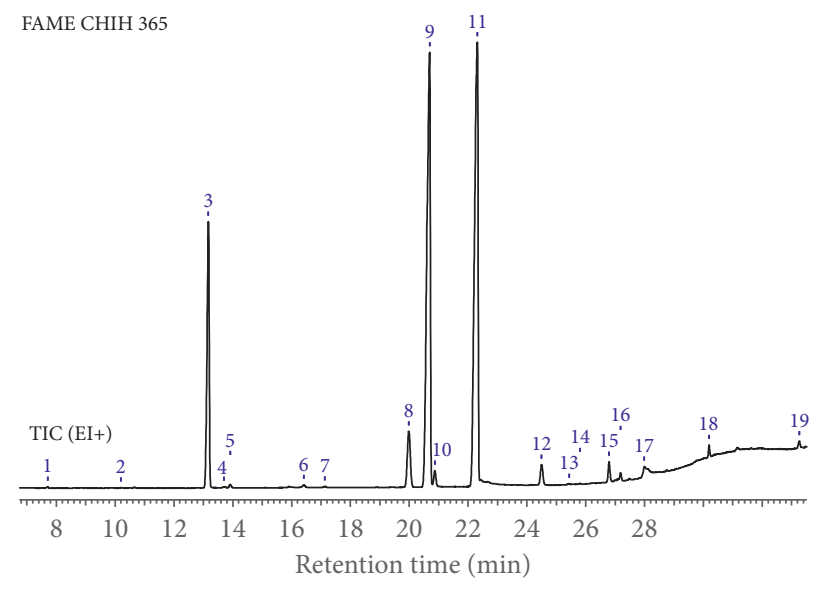

Figure 1: FAME profile of analysed maize sample. 
TABLe 2: Sterol profile $(\mathrm{mg} / 100 \mathrm{~g})$ of the blue and yellow corn.

\begin{tabular}{lcccccc}
\hline No. & Sterols & CHIH 365 & CHIH 367 & CHIH 503 & OPOKA & KUSKUN \\
\hline $\mathbf{1}$ & Campesterol & $11.68 \pm 1.12 \mathrm{~b}$ & $12.48 \pm 1.34 \mathrm{a}$ & $9.56 \pm 0.92 \mathrm{c}$ & $12.26 \pm 1.04 \mathrm{~b}$ & $11.87 \pm 1.14 \mathrm{~b}$ \\
$\mathbf{2}$ & Campestanol & $2.72 \pm 0.08 \mathrm{c}$ & $2.98 \pm 0.08 \mathrm{~b}$ & $2.79 \pm 0.0 \mathrm{c}$ & $1.84 \pm 0.04 \mathrm{~d}$ & $3.07 \pm 0.09 \mathrm{a}$ \\
$\mathbf{3}$ & Stigmasterol & $4.97 \pm 0.42 \mathrm{~b}$ & $5.12 \pm 0.49 \mathrm{a}$ & $3.75 \pm 0.31 \mathrm{~d}$ & $3.62 \pm 0.34 \mathrm{~d}$ & $4.54 \pm 0.35 \mathrm{c}$ \\
$\mathbf{4}$ & $\beta$-Sitosterol & $35.35 \pm 4.12 \mathrm{~b}$ & $36.60 \pm 3.87 \mathrm{~b}$ & $33.07 \pm 3.04 \mathrm{c}$ & $44.23 \pm 4.33 \mathrm{a}$ & $33.10 \pm 3.07 \mathrm{c}$ \\
$\mathbf{5}$ & Stigmastanol & $14.42 \pm 0.86 \mathrm{a}$ & $12.02 \pm 0.53 \mathrm{c}$ & $13.55 \pm 0.71 \mathrm{~b}$ & Trace & $8.90 \pm 0.38 \mathrm{~d}$ \\
$\mathbf{6}$ & D-7 avenasterol & Trace & Trace & $4.01 \pm 0.11 \mathrm{~b}$ & Trace & $6.80 \pm 0.78 \mathrm{a}$ \\
$\mathbf{7}$ & Stigmasta-7,22-dien-3-ol & $1.66 \pm 0.05 \mathrm{a}$ & Trace & $1.68 \pm 0.07 \mathrm{a}$ & Trace & $0.78 \pm 0.03 \mathrm{~b}$ \\
$\mathbf{8}$ & Stigmasta-3,5-dien & Trace & Trace & Trace & $6.85 \pm 0.09 \mathrm{a}$ & Trace \\
\hline
\end{tabular}

a-d: homogeneous groups according to Duncan's test.

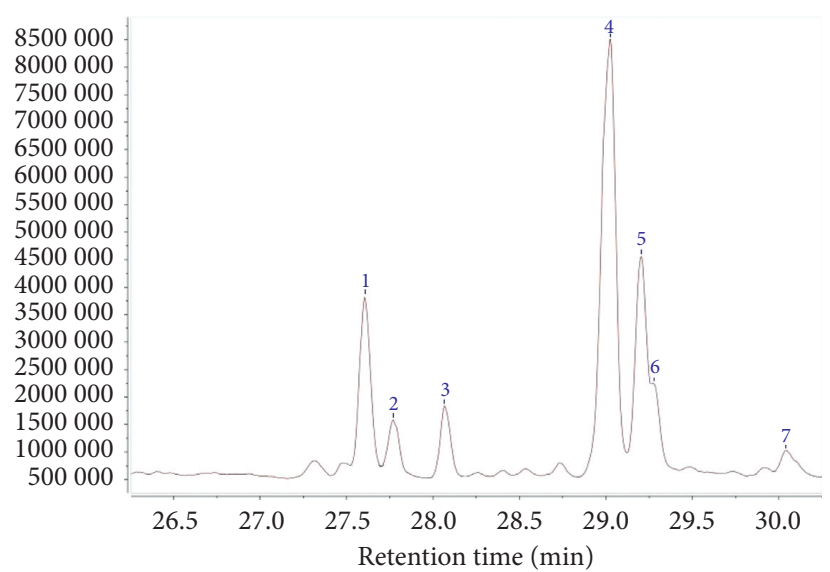

Figure 2: The chromatogram presents the sterol blue corn line profile CHIH 503 (1-campesterol, 2-stigmastanol, 3-stigmasterol, 4- $\beta$ sitosterol, 5-stigmastanol, 6-campestanol, and 7-stigmasta-7,22-dien-3-ol).

yellow corn varieties (OPOKA, KUSKUN), no anthocyanins were identified.

Figure 3 shows the chromatogram of the anthocyanin profile detected in the blue corn line $\mathrm{CHIH} \mathrm{503.} \mathrm{The} \mathrm{antho-}$ cyanin profile in the blue corn lines was similar to the data in the literature. In the studies carried out by Vázquez-Carrillo et al. [40], nine anthocyanins were identified. The one found in the largest amount was cyanidin-3-(6'-malonylglucoside), followed by cyanidin-3-glucoside. According to the research carried out by Nankar et al. [3], five main anthocyanin compounds were determined from the Mexican blue corn variety in the anthocyanin profile: cyanidin-3-glucoside, pelargonidin-3-glucoside, peonidin-3-glucoside, cyanidin-3succinylglucoside, and cyanidin-3-disuccinylglucoside [3]. In our work, the number of analysed anthocyanins was about three times lower compared to Vázquez-Carrillo et al. [40], where the authors quantified $655 \mathrm{mg} / \mathrm{kg}$ of flavonoids in BCE. Researchers studying the structure of blue corn have reported a total of 16 different anthocyanidins appearing in the profile of this corn variety, based on the spectrophotometric and chromatographic analysis. The content of anthocyanins in blue corn may vary depending on many factors, such as the extraction method used, the type of analysis carried out, climatic conditions related to geographical location, temperature, and environmental factors [41-44].
3.4.2. Phenolic Acids. In the conducted studies of phenolic acid compounds, in blue corn lines and in yellow corn varieties, nine dominating compounds were determined. In all the tested lines of blue corn and in the yellow variety, a similar profile of phenolic acids was identified. Such acids and flavanols as caffeic acid, procyanidin B2, gallic acid, (-)-epicatechin, neochlorogenic acid, chlorogenic acid, sinapic acid, protocatechuic acid, and ferulic acid were found (Table 4).

Based on Table 4, showing the average in all of the tested varieties and lines, caffeic acid was found in the highest amount (274.97-544.65 mg/kg), and sinapic acid was found in the smallest amount $(3.99-7.70 \mathrm{mg} / \mathrm{kg})$. Large quantities of ferulic acid, gallic acid, and procyanidin B2 were also found.

The largest amount of phenolic acids occurred in the blue corn line CHIH 503, and the least amount of polyphenolic acids occurred in the yellow variety.

From the data in the literature in studies carried out on a yellow, white, and violet corn variety, a similar profile of polyphenol compounds to those determined in the above studies was identified. Acids such as gallic acid, protocatechuic acid, ferulic acid, sinapic acid, and quercetin were noted. Ferulic acid and quercetin were identified in the largest amounts in all tested variants [45]. 
Table 3: Profile of polyphenolic compounds-anthocyanins_in the tested maize varieties (mg/kg of dry matter).

\begin{tabular}{lccccccc}
\hline No. & RT & Anthocyanins & CHIH 365 & CHIH 367 & CHIH 503 & OPOKA & KUSKUN \\
\hline $\mathbf{1}$ & 8.11 & Cyanidin-3-glucoside & $36.33 \pm 2.24 \mathrm{a}$ & $38.21 \pm 3.01 \mathrm{a}$ & $36.76 \pm 2.21 \mathrm{a}$ & n.d. & n.d. \\
$\mathbf{2}$ & 9.70 & Pelargonidin-3-glucoside & $0.11 \pm 0.01 \mathrm{c}$ & $0.17 \pm 0.01 \mathrm{a}$ & $0.15 \pm 0.01 \mathrm{~b}$ & n.d. & n.d. \\
$\mathbf{3}$ & 10.00 & Pelargonidin-3-galactoside & $2.41 \pm 0.23 \mathrm{c}$ & $3.79 \pm 0.28 \mathrm{a}$ & $3.35 \pm 0.21 \mathrm{~b}$ & n.d. & n.d. \\
$\mathbf{4}$ & 10.50 & Peonidin-3-glucoside & $12.71 \pm 1.07 \mathrm{a}$ & $13.77 \pm 1.29 \mathrm{a}$ & $9.73 \pm 0.98 \mathrm{~b}$ & n.d. & n.d. \\
$\mathbf{5}$ & 11.57 & Cyanidin-3-(6'-malonylglucoside) & $80.79 \pm 4.08 \mathrm{~b}$ & $92.35 \pm 4.76 \mathrm{a}$ & $96.58 \pm 5.03 \mathrm{a}$ & n.d. & n.d. \\
$\mathbf{6}$ & 13.00 & Pelargonidin-3-(6'-malonyglucoside) & $12.52 \pm 1.11 \mathrm{~b}$ & $14.62 \pm 1.23 \mathrm{a}$ & $9.09 \pm 0.64 \mathrm{c}$ & n.d. & n.d. \\
$\mathbf{7}$ & 13.23 & Peonidin-3-(6'malonyglucoside) & $6.32 \pm 0.67 \mathrm{a}$ & $6.89 \pm 0.83 \mathrm{a}$ & $3.34 \pm 0.31 \mathrm{~b}$ & n.d. & n.d. \\
$\mathbf{8}$ & 13.69 & Peonidin-3-(6'malonyglucoside) & $31.63 \pm 2.46 \mathrm{~b}$ & $34.47 \pm 2.65 \mathrm{a}$ & $16.7 \pm 1.87 \mathrm{c}$ & n.d. & n.d. \\
$\mathbf{9}$ & - & In total: & 182.82 & 204.27 & 175.7 & - & - \\
\hline
\end{tabular}

a-c-homogeneous groups according to Duncan's test; n.d.—not detected; limit of detection for comp. 1, 5, and 8-approx. $4 \mu \mathrm{g} / \mathrm{Table} 100 \mathrm{~mL}$, for comp. 2, 3, and $4 \mu \mathrm{g} / 100 \mathrm{~mL}$ and 2 for 7,8 .

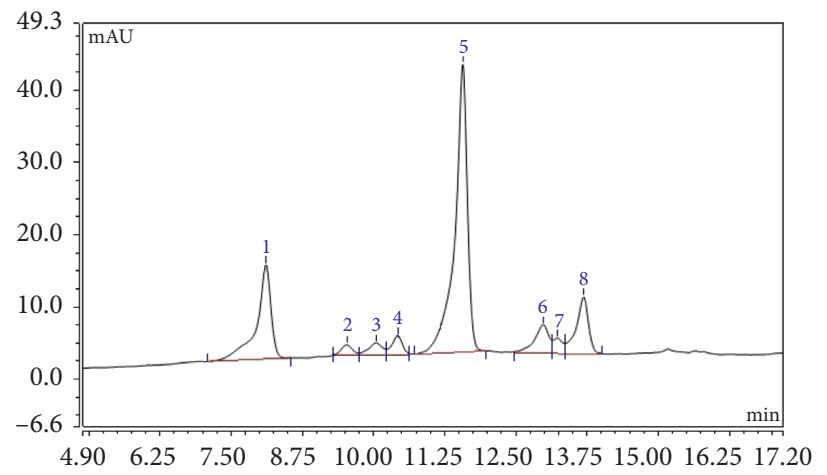

Figure 3: The chromatogram of polyphenol compounds-anthocyanins of blue maize line CHIH 503. Identified anthocyanins are 1-cyanidin-3glucoside, 2-pelargonidin-3-glucoside, 3-pelargonidin-3-glucoside, 4-peonidin-3-glucoside, 5-cyanidin-3-(6' ${ }^{\prime}$-malonylglucoside), 6-pelargonidin-3-(6'-malonylglucoside), 7-peonidin-3-(6'-malonylglucoside), and 8-peonidin-3-(6-malonylglucoside).

3.5. Antidiabetic Activity. The results regarding antidiabetic activity (Table 5) show that extracts from the blue and yellow corn varieties, in the absence of dilution, inhibit the $\alpha$-amylase effect by $100 \%$. At 5 -fold dilution, extracts from KUSKUN inhibit the tested enzyme activity by $90 \%$. At a 10 fold dilution and 25-fold dilution, only the extract from the blue corn $\mathrm{CHIH} 365$ inhibited the $\alpha$-amylase activity by $100 \%$. The other BCE showed inhibition of $55-29 \%$, OPOKA extract was $12 \%$, and KUSKUN extract was inactive.

$\alpha$-Amylase and $\alpha$-glucosidase are the main enzymes involved in the breakdown of sugars in the human body [46]. Pancreatic $\alpha$-amylase is responsible for the breakdown of starch into oligosaccharides, and intestinal $\alpha$-glucosidase is involved in the hydrolysis of oligosaccharides, as well as triand disaccharides, to glucose molecules and other monosaccharides [46]. Inhibitors of these enzymes contribute to lowering postprandial hyperglycemia and slowing carbohydrate digestion in people with diabetes [47].

Numerous studies have proven that plant extracts rich in anthocyanins, which are responsible for prohealth effects in the human body, also show antidiabetic activity by inhibiting $\alpha$-amylase and $\alpha$-glucosidase activity $[48,49]$. In the research carried out by Nowicka et al. [50], it was shown that antioxidant activity correlates with antidiabetic activity, anthocyanins and flavonol inhibit the activity of $\alpha$-glucosidase, and flavone-3-ol inhibits $\alpha$-amylase. In studies carried out on pears by Wang et al. [51], a correlation between anthocyanin activities and antidiabetic activity was also shown. Flavonoids and phenolic acids (ferulic acid, chlorogenic acid, and rutin), which have significant antioxidant activity, inhibit polysaccharide hydrolyzing enzymes. However, in the case of BCE, compounds in the fat fraction are responsible for the antidiabetic activity. This may be due to a much higher concentration of these compounds compared to the concentration of polyphenolic compounds in the obtained extracts $[52,53]$.

Tests for $\alpha$-amylase inhibition activity have shown that the fraction containing free fatty acids (Fraction I) is the most active (see Table 6). The extract and 5-fold dilution showed 100\% inhibition. The triacylglycerol and sterol fraction (Fractions II and III) and their 5-fold dilution showed low activity of about $6 \%$. The fraction containing polyphenols (Fraction IV) was characterized by the lowest $\alpha$-amylase inhibition after dilution. 
TABle 4: Profile of phenolic acids quantified $(\mathrm{mg} / \mathrm{kg})$ in the tested maize varieties.

\begin{tabular}{lcccc}
\hline Phenolic acids & CHIH 365 & CHIH 367 & CHIH 503 & OPOKA \\
\hline Gallic acid & $154.01 \pm 8.76 \mathrm{c}$ & $163.75 \pm 8.63 \mathrm{~b}$ & $108.85 \pm 6.92 \mathrm{~d}$ & $190.48 \pm 9.11 \mathrm{a}$ \\
Protocatechuic acid & $9.09 \pm 0.65 \mathrm{c}$ & $9.78 \pm 0.79 \mathrm{~b}$ & $10.78 \pm 0.78 \mathrm{~b}$ & $36.87 \pm 2.85 \mathrm{a}$ \\
(-)-Epicatechin & - & $15.67 \pm 1.08 \mathrm{~b}$ & $21.57 \pm 1.87 \mathrm{a}$ & $9.07 \pm 0.86 \mathrm{c}$ \\
Chlorogenic acid & $95.66 \pm 4.98 \mathrm{~b}$ & $87.13 \pm 4.05 \mathrm{c}$ & $165.42 \pm 8.66 \mathrm{a}$ & $72.94 \pm 3.61 \mathrm{~d}$ \\
Neochlorogenic acid & $66.21 \pm 2.11 \mathrm{c}$ & $118.25 \pm 7.04 \mathrm{~b}$ & $134.34 \pm 5.78 \mathrm{a}$ & $23.18 \pm 2.02 \mathrm{~d}$ \\
Procyanidin B2 & $101.96 \pm 6.77 \mathrm{~b}$ & $93.18 \pm 4.888 \mathrm{c}$ & $154.38 \pm 6.93 \mathrm{a}$ & $76.12 \pm 4.13 \mathrm{~d}$ \\
Caffeic acid & $304.65 \pm 12.28 \mathrm{c}$ & $323.79 \pm 13.12 \mathrm{~b}$ & $544.65 \pm 15.28 \mathrm{a}$ & $274.97 \pm 11.32 \mathrm{~d}$ \\
Ferulic acid & $185.24 \pm 9.26 \mathrm{c}$ & $105.35 \pm 6.94 \mathrm{~d}$ & $246.88 \pm 10.73 \mathrm{a}$ & $230.07 \pm 10.98 \mathrm{~b}$ \\
Sinapic acid & $4.56 \pm 0.51 \mathrm{c}$ & $3.99 \pm 0.26 \mathrm{~d}$ & $7.70 \pm 0.54 \mathrm{a}$ & $7.04 \pm 0.47 \mathrm{~b}$ \\
In total: & 921.38 & 920.89 & 1394.57 & 920.74 \\
\hline
\end{tabular}

a-d: homogeneous groups according to Duncan's test.

TABLe 5: Antidiabetic activity of the tested extracts expressed in \% inhibition of $\alpha$-amylase.

\begin{tabular}{|c|c|c|c|c|c|c|}
\hline \multicolumn{7}{|c|}{ Percentage of inhibition (\%) } \\
\hline Corn type (line) & Extract & 5-fold dilution & 10-fold dilution & 25-fold dilution & 50-fold dilution & 100-fold dilution \\
\hline CHIH 365 & $100.0 \pm 0.00 \mathrm{a}$ & $100.0 \pm 0.00 \mathrm{a}$ & $100 \pm 0.00 \mathrm{a}$ & $100.0 \pm 0.00 \mathrm{a}$ & $75.0 \pm 3.5 \mathrm{a}$ & $54.6 \pm 3.1 \mathrm{a}$ \\
\hline CHIH 367 & $100.0 \pm 0.00 \mathrm{a}$ & $100.0 \pm 0.00 \mathrm{a}$ & $73.0 \pm 2.00 \mathrm{a}$ & $60.0 \pm 2.1 \mathrm{a}$ & $50.0 \pm 2.0 \mathrm{a}$ & $50.6 \pm 2.2 \mathrm{a}$ \\
\hline CHIH 503 & $100.0 \pm 0.00 \mathrm{a}$ & $100.0 \pm 0.00 \mathrm{a}$ & $61.0 \pm 3.00 \mathrm{a}$ & $58.0 \pm 3.2 \mathrm{a}$ & $32.0 \pm 2.0 \mathrm{a}$ & $28.9 \pm 1.5 b$ \\
\hline OРОКА & $100.0 \pm 0.00 \mathrm{a}$ & $100.0 \pm 0.00 \mathrm{a}$ & $47.0 \pm 2.1 \mathrm{a}$ & $40.0 \pm 2.70 \mathrm{a}$ & $33.3 \pm 0.00 \mathrm{~b}$ & $12.3 \pm 0.5 \mathrm{a}$ \\
\hline KUSKUN & $100.0 \pm 0.00 \mathrm{a}$ & $90.0 \pm 3.9 \mathrm{a}$ & $51.7 \pm 4.6 \mathrm{a}$ & $42.3 \pm 4.1 \mathrm{a}$ & Trace & Trace \\
\hline
\end{tabular}

a-b: homogeneous groups according to Duncan's test.

TAвle 6: Antidiabetic activity of the tested extracts (obtained after conducting preparative thin-layer chromatography) expressed in \% inhibition of $\alpha$-amylase.

\begin{tabular}{|c|c|c|c|c|c|}
\hline \\
\hline \multicolumn{6}{|c|}{$\begin{array}{l}\text { Percentage of inhibition (\%) } \\
\text { Corn line CHIH } 365\end{array}$} \\
\hline Fraction I fatty acids & $100.00 \pm 0.00 \mathrm{a}$ & $100.00 \pm 0.00 \mathrm{a}$ & $93.75 \pm 6.25 a$ & $60.78 \pm 19.61 \mathrm{a}$ & $33.29 \pm 2.00 \mathrm{a}$ \\
\hline Fraction II TAG & $17.65 \pm 5.49 c$ & $5.88 \pm 1.96 c$ & Trace & Trace & Trace \\
\hline Fraction III sterols & $12.50 \pm 3.13 \mathrm{~d}$ & $6.25 \pm 2.08 c$ & Trace & Trace & Trace \\
\hline Fraction IV polyphenols & $15.00 \pm 2.50 c$ & Trace & Trace & Trace & Trace \\
\hline
\end{tabular}

a-d: homogeneous groups according to Duncan's test.

\section{Conclusions}

The search for novel compounds and natural plant extracts as potential inhibitors of carbohydrate metabolizing enzymes has intensified in recent years. The present study demonstrated that all tested corn cultivars showed antidiabetic activity as $\alpha$-amylase inhibitors, compared to acarbose. The strongest antidiabetic action was found in the line of blue corn CHIH 365 and its fatty acids fraction. The blue corn lines were richer in bioactive compounds (polyphenolic compounds-anthocyanins, especially cyanidin-3-(6'-malonylglucoside) and pelargonidin-3$\left(6^{\prime}\right.$-malonyglucoside $)$ than the yellow corn varieties studied, and the lipid fraction (rich in oleic and linoleic fatty acids) was responsible for the $\alpha$-amylase inhibition activity rather than the polyphenol fraction. Obtained extracts require additional structural elucidation to identify the active constituents. Moreover, further ex vivo and in vivo investigations should be done for confirming the antidiabetic activity of the extracts and to evaluate the mechanism of action.

\section{Data Availability}

All data included in this study are available from the corresponding author upon request.

\section{Conflicts of Interest}

The authors declare that they have no conflicts of interest regarding the publication of this paper.

\section{Acknowledgments}

This work was supported by Wrocław Centre of Biotechnology and the Leading National Research Centre (KNOW) program for years 2014-2018. The publication was the result of the activity of the research group "Plants4food."

\section{Supplementary Materials}

The Supplementary Materials include the comprehensive image analysis. (Supplementary Materials) 


\section{References}

[1] L. Głąb and J. Sowiński, "Kukurydza niebieskoziarnowa-charakterystyka i znaczenie," Kukurydza, vol. 2, no. 49, pp. 53-55, 2016.

[2] C. Mutlu, S. Arslan-Tontul, C. Candal, O. Kilic, and M. Erbas, "Physicochemical, thermal, and sensory properties of blue corn (Zea Mays L.)," Journal of Food Science, vol. 83, no. 1, pp. 53-59, 2018.

[3] A. N. Nankar, B. Dungan, N. Paz et al., "Quantitative and qualitative evaluation of kernel anthocyanins from southwestern United States blue corn," Journal of the Science of Food and Agriculture, vol. 96, no. 13, pp. 4542-4552, 2016.

[4] G. A. Camelo-Méndez, E. Agama-Acevedo, J. Tovar, and L. A. Bello-Pérez, "Functional study of raw and cooked blue maize flour: starch digestibility, total phenolic content and antioxidant activity," Journal of Cereal Science, vol. 76, pp. 179-185, 2017.

[5] A. N. Nankar, M. P. Scott, and R. C. Pratt, "Compositional analyses reveal relationships among components of blue maize grains," Plants, vol. 9, no. 12, p. 1775, 2020.

[6] K. Damian-Medina, Y. Salinas-Moreno, D. Milenkovic et al., "In silico analysis of antidiabetic potential of phenolic compounds from blue corn (Zea mays L.) and black bean (Phaseolus vulgaris L.)," Heliyon, vol. 6, pp. 1-13, 2020.

[7] C. de la Parra, S. O. Serna Saldivar, and R. H. Liu, "Effect of processing on the phytochemical profiles and antioxidant activity of corn for production of masa, tortillas, and tortilla chips," Journal of Agricultural and Food Chemistry, vol. 55, no. 10, pp. 4177-4183, 2007.

[8] D. J. Bhuyan and A. Basu, "Phenolic compounds: potential health benefits and toxicity," Utilisation of Bioactive Compounds from Agricultural and Food Waste, vol. 2, pp. 27-59, 2017.

[9] T. Ozcan, A. Akpinar-Bayizit, L. Yilmaz-Ersan, and B. Delikanli, "Phenolics in human health," International Journal of Chemical Engineering and Applications, vol. 5, no. 5, pp. 393-396, 2014.

[10] M. G. Miguel, "Anthocyanins: antioxidant and/or anti-inflammatory activities," Journal of Pharmaceutical Sciences, vol. 1, pp. 7-15, 2011.

[11] M. Szaniawska, A. Taraba, and K. Szymczyk, "Budowa, właściwości i zastosowanie antocyjanów,” Nauki Inżynierskie I Technologie, vol. 17, no. 2, pp. 1-19, 2015.

[12] P. Somavat, D. Kumar, and V. Singh, "Techno-economic feasibility analysis of blue and purple corn processing for anthocyanin extraction and ethanol production using modified dry grind process," Industrial Crops and Products, vol. 115, pp. 78-87, 2018.

[13] M. Á. Sánchez-Madrigal, A. Quintero-Ramos, C. A. AmayaGuerra, C. O. Meléndez-Pizarro, S. L. Castillo-Hernández, and C. J. Aguilera-González, "Effect of agave fructans as carrier on the encapsulation of blue corn anthocyanins by spray drying," Foods, vol. 8, no. 7, p. 268, 2019.

[14] K. Hasanudin, P. Hashim, and S. Mustafa, "Corn silk (Stigma maydis) in healthcare: a phytochemical and pharmacological review," Molecules, vol. 17, no. 8, pp. 9697-9715, 2012.

[15] J. Wang, M. Huang, J. Yang et al., "Anti-diabetic activity of stigmasterol from soybean oil by targeting the GLUT4 glucose transporter," Food \& Nutrition Research, vol. 61, no. 1, p. $1364117,2017$.
[16] L. Xie, J. Mo, J. Ni et al., "Structure-based design of human pancreatic amylase inhibitors from the natural anthocyanin database for type 2 diabetes," Food \& Function, vol. 11, no. 4, pp. 2910-2923, 2020.

[17] N. Karim, M. A. Rahman, S. Changlek, and J. Tangpong, "Short-time administration of xanthone from Garcinia mangostana fruit pericarp attenuates the hepatotoxicity and renotoxicity of type II diabetes mice," Journal of the American College of Nutrition, vol. 39, no. 6, pp. 501-510, 2020.

[18] S. Sabiu, F. H. O’Neill, and A. O. T. Ashafa, "Kinetics of $\alpha$-amylase and $\alpha$-glucosidase inhibitory potential of Zea mays Linnaeus (Poaceae), Stigma maydis aqueous extract: an in vitro assessment," Journal of Ethnopharmacology, vol. 183, pp. 1-8, 2016.

[19] A. Nawirska-Olszańska, B. Stępień, and A. Biesiada, "Effectiveness of the fountain-microwave drying method in some selected pumpkin cultivars," LWT-Food Science and Technology, vol. 77, pp. 276-281, 2017.

[20] A. Nawirska-Olszańska, B. Stępień, A. Biesiada, J. KolniakOstek, and M. Oziembłowski, "Rheological, chemical and physical characteristics of golden berry (Physalis peruviana L.) after convective and microwave drying," Foods, vol. 6, no. 8, p. $60,2017$.

[21] R. Manikandan, A. Vijaya Anand, and G. Durai Muthumani, "Phytochemical and in vitro anti-diabetic activity of methanolic extract of Psidium guajava leaves," International Journal of Current Microbiology and Applied Sciences, vol. 2, pp. 15-19, 2013.

[22] M. N. Akhtar and M. G. Mahalingam, "Anti-oxidant, antimicrobial and glucose diffusion inhibition activities of the aqueous and chloroform extract of Phyllanthus urinaria," International Journal of Pharmacy and Pharmaceutical Sciences, vol. 8, pp. 278-280, 2016.

[23] R. Kupczyński, A. Szumny, M. Bednarski et al., "Application of Pontentilla anserine, polygonum aviculare and Rumex crispus mixture extracts in a rabbit model with experimentally induced E. coli infection," Animals, vol. 9, p. 774, 2019.

[24] L. Y. W. Chua, B. L. Chua, A. Figiel et al., "Drying of Phyla nodiflora leaves: antioxidant activity, volatile and phytosterol content, energy consumption, and quality studies," Processes, vol. 7, no. 4, p. 210, 2019.

[25] A. Z. Kucharska, A. Szumny, A. Sokół-Łętowska, N. Piórecki, and S. V. Klymenko, "Iridoids and anthocyanins in cornelian cherry (Cornus mas L.) cultivars," Journal of Food Composition and Analysis, vol. 40, pp. 95-102, 2015.

[26] D. A. Urias-Lugo, J. B. Heredia, J. B. Valdez-Torres, M. D. Muy-Rangel, S. O. Serna-Saldivar, and S. García-Lara, "Physical properties and chemical characterization of macroand micro-nutriments of elite blue maize hybrids (Zea mays L.)," Cereal Research Communications, vol. 43, no. 2, pp. 295-306, 2015.

[27] S. Harrabi, F. S. Sakouhi, A. St-Amand, S. B. Boukhchina, H. K. Kallel, and P. M. Mayer, "Accumulation of phytosterols, triterpene alcohols and phytostanols in developing Zea mays L. kernels," Journal of Plant Sciences, vol. 2, no. 3, pp. 260-272, 2007.

[28] S. Harrabi, A. St-Amand, F. Sakouhi et al., "Phytostanols and phytosterols distributions in corn kernel," Food Chemistry, vol. 111, no. 1, pp. 115-120, 2008.

[29] R. A. Moreau, A.-M. Lampi, and K. B. Hicks, "Fatty acid, phytosterol, and polyamine conjugate profiles of edible oils 
extracted from corn germ, corn fiber, and corn kernels," Journal of the American Oil Chemists' Society, vol. 86, no. 12, p. 1209, 2009.

[30] S. P. Choudhary and L. S. Tran, "Phytosterols: perspectives in human nutrition and clinical therapy," Current Medicinal Chemistry, vol. 18, no. 29, pp. 4557-4567, 2011.

[31] K. Nomaguchi, M. Tanaka, E. Misawa et al., "Aloe vera phytosterols act as ligands for PPAR and improve the expression levels of PPAR target genes in the livers of mice with diet-induced obesity," Obesity Research \& Clinical Practice, vol. 5, pp. 190-201, 2011.

[32] E. Misawa, M. Tanaka, K. Nomaguchi et al., "Administration of phytosterols isolated from Aloe vera gel reduce visceral fat mass and improve hyperglycemia in Zucker diabetic fatty (ZDF) rats," Obesity Research \& Clinical Practice, vol. 2, no. 4, pp. 239-245, 2008.

[33] D. Reddy, I. Muchandi, R. Srinivasa et al., "Effect of Holostemma annularis on the progression of diabetes induced by a high fructose diet in rats and in diabetic C57BL/6J ob/ob mice," Diabetes, Metabolic Syndrome and Obesity, vol. 3, pp. 87-94, 2010.

[34] A. Shirwaikar, I. S. R. Punitha, M. Upadhye, and A. Dhiman, "Antidiabetic activity of alcohol root extract ofHolostemma annulare. In NIDDM rats," Pharmaceutical Biology, vol. 45, no. 6, pp. 440-445, 2007.

[35] Z. Sheng, H. Dai, S. Pan et al., "Phytosterols in banana (Musa spp.) flower inhibit $\alpha$-glucosidase and $\alpha$-amylase hydrolysations and glycation reaction," International Journal of Food Science \& Technology, vol. 52, no. 1, pp. 171-179, 2017.

[36] B. Wang, T. Xiao, J. Ruan, and W. Liu, "Beneficial effects of corn silk on metabolic syndrome," Current Pharmaceutical Design, vol. 23, no. 34, pp. 5097-5103, 2017.

[37] N. Payghami, S. Jamili, A. Rustaiyan et al., "Alpha-amylase inhibitory activity and sterol composition of the marine algae, Sargassum glaucescens," Pharmacognosy Research, vol. 7, p. 314, 2015.

[38] P. Dais and E. Hatzakis, "Quality assessment and authentication of virgin olive oil by NMR spectroscopy: a critical review," Analytica Chimica Acta, vol. 765, pp. 1-27, 2013.

[39] T. Parker, E. Limer, A. D. Watson, M. Defernez, D. Williamson, and E. K. Kemsley, " $60 \mathrm{MHz} 1 \mathrm{H}$ NMR spectroscopy for the analysis of edible oils," TrAC Trends in Analytical Chemistry, vol. 57, pp. 147-158, 2014.

[40] M. G. Vázquez-Carrillo, L. A. Aparicio-Eusebio, Y. SalinasMoreno, M. O. Buendía-Gonzalez, and D. Santiago-Ramos, "Nutraceutical, physicochemical, and sensory properties of blue corn polvorones, a traditional flour-based confectionery," Plant Foods for Human Nutrition, vol. 73, no. 4, pp. 321-327, 2018.

[41] D. D. Pozo-Insfran, C. H. Brenes, S. Serna, and S. T. Talcott, "Polyphenolic and antioxidant content of white and blue corn (Zea mays L.) products," Food Research International, vol. 39, pp. 696-703, 2006.

[42] E.-S. M. Abdel-Aal, J. C. Young, and I. Rabalski, "Anthocyanin composition in black, blue, pink, purple, and red cereal grains," Journal of Agricultural and Food Chemistry, vol. 54, no. 13, pp. 4696-4704, 2006.

[43] T. Fossen, R. Slimestad, and Ø. M. Andersen, “Anthocyanins from maize (Zea mays) and reed canarygrass (phalaris arundinacea)," Journal of Agricultural and Food Chemistry, vol. 49, no. 5, pp. 2318-2321, 2001.

[44] L. X. Lopez-Martinez, R. M. Oliart-Ros, G. Valerio-Alfaro, C.-H. Lee, K. L. Parkin, and H. S. Garcia, "Antioxidant activity, phenolic compounds and anthocyanins content of eighteen strains of Mexican maize," LWT - Food Science and Technology, vol. 42, no. 6, pp. 1187-1192, 2009.

[45] S. Trehan, N. Singh, and A. Kaur, "Characteristics of white, yellow, purple corn accessions: phenolic profile, textural, rheological properties and muffin making potential," Journal of Food Science and Technology, vol. 55, no. 6, pp. 2334-2343, 2018.

[46] S. S. Nair, V. Kavrekar, and A. Mishra, "In vitro studies on alpha amylase and alpha glucosidase inhibitory activities of selected plant extracts," European Journal of Experimental Biology, vol. 3, pp. 128-132, 2013.

[47] M. Figueriredo-González, P. Reboredo-Rodriguez, C. GonzálezBarreiro et al., "Evaluation of the neuroprotective and antidiabetic potential of phenol-rich extracts from virgin olive oils by in vitro assays," Food Research International, vol. 106, pp. 558-567, 2018.

[48] S. Akkarachiyasit, P. Charoenlertkul, S. Yibchok-anun, and S. Adisakwattana, "Inhibitory activities of cyanidin and its glycosides and synergistic effect with acarbose against intestinal $\alpha$-glucosidase and pancreatic $\alpha$-amylase," International Journal of Molecular Sciences, vol. 11, no. 9, pp. 3387-3396, 2010.

[49] L. Mojica, M. Berhow, and E. Gonzalez de Mejia, "Black bean anthocyanin-rich extracts as food colorants: physicochemical stability and antidiabetes potential," Food Chemistry, vol. 229, pp. 628-639, 2017.

[50] P. Nowicka, A. Wojdyło, and J. Samoticha, "Evaluation of phytochemicals, antioxidant capacity, and antidiabetic activity of novel smoothies from selected Prunus fruits," Journal of Functional Foods, vol. 25, pp. 397-407, 2016.

[51] T. Wang, X. Li, B. Zhou, H. Li, J. Zeng, and W. Gao, "Antidiabetic activity in type 2 diabetic mice and $\alpha$-glucosidase inhibitory, antioxidant and anti-inflammatory potential of chemically profiled pear peel and pulp extracts (Pyrus spp.)," Journal of Functional Foods, vol. 13, pp. 276-288, 2015.

[52] A. I. Martinez-Gonzalez, Á. G. Díaz-Sánchez, L. A. d. l. Rosa, C. L. Vargas-Requena, I. Bustos-Jaimes, and A. E. AlvarezParrilla, "Polyphenolic compounds and digestive enzymes: in vitro non-covalent interactions," Molecules, vol. 22, no. 4, p. 669, 2017.

[53] S. Uysal, G. Zengin, A. Aktumsek, and S. Karatas, "Fatty acid composition, total sugar content and anti-diabetic activity of methanol and water extracts of nine different fruit tree leaves collected from mediterranean region of Turkey," International Journal of Food Properties, vol. 18, no. 10, pp. 2268-2276, 2015. 